prevented from uniting. But in doing so he must bear in mind that the waters of Ulenge, made by him to be the recipient of the Kassavi, as well as of the Chambeze, are said by some of Livingstone's native informants to flow N.N.W. into Chowambe or Albert Nyanza, and that for the westerly extension of this body of water we have the authority of Baker.

On the subject of the Congo I have little to say. If it should be found that north of the fifth parallel of south latitude the basin of that river requires to be carried further eastward than the 2oth meridian, I see no objection to it. Only I am bound to remark, that I do not consider there is any warrant for representing the Congo as a river having a low alluvial valley extending some 500 or 600 miles inland. have not examined the subject of this river very closely, but my impression is, that, like the other rivers of the West Coast of Africa south of the equator, the rise of the level of its bed is rapid, and that it becomes considerable within a short distance from the ocean ; so that there would not be sufficient fall for the waters of Ulenge in $27^{\circ} 30^{\prime} \mathrm{E}$. long. to join it. And, further, I cannot but entertain the opinion that the volume of water of the Congo has been greatly over estimated; in support of which opinion I will cite the following passages, in pages 147 and 148 , of Captain Tuckey's Narrative :- " At the further end of the banza we unexpectedly saw the fall almost under our feet, and were not less surprised than disappointed at finding, instead of a second Niagara, which the description of the natives and their horror of it had given us reason to expect, a comparative brook bubbling over its stony bed ... . The principal idea that the fall creates is, that the quantity of water which flows over it is by no means equal to the volume of the river below it and yet, as we know there is not at this season a tributary stream sufficient to turn a mill below the fall, we can hardly account for this volume, unless we suppose, as Dr. Smith suggests, the existence of subterranean communications or caverns filled with water." Does this look like the lower course of the supposed second great river of Africa, with a basin of which the area is estimated to measure 800,000 square miles?

On a reconsideration, then, of the whole subject, I see no reason whatever to go from the opinion I have expressed, that the rivers Kassavi and Chambeze unite to form the upper course of the Albert Nyanza; that is to say, the main stream of the Nile; and as the former of those two rivers has the more direct course, and its sonrce is the most remote of all, it is entitled to the honour which I claim for it, of being the hitherto undiscovered head of the great river of Egypt.

Bekesbourne, April 22 - Since the foregoing was written, Mr. Keith Jake "Map of the Lake Region of Eastern Africa," with notes, just published, in which I find a categorical answer to my question respecting the western limits of the Upper Nile Basin. He traces them as coming from the south of Lake Liemba and its feeders, and running close along the western side of Tanganyika as far as its northern end, where he gives them a curve to the westward not more than sufficient to include the south-western of the Albert Nyanza, and thence continuing along the high mountains on the west side of that body of water, the westerly extension of which, reported by Baker, he ignores entirely. To these views I need not reiterate my objections.

C. B.

\section{Why is the Sky Blue?}

CAN any of your readers inform me why the sky is blue? Is it that the predominant colour of sunlight being orange, the regions devoid of sunlight appear of the complementary colour? If so, the planets of Sirius and Vega would have a black sky, those of Betelgeux a green sky, while those of the double stars would have different coloured skies at different times, according to their position with respect to their two luminaries. Or again, is the blueness merely the colour of our atmosphere, as Prof. Tyndall's experiments have led some to believe? In favour of the former explanation, is the fact that the maximum intensity of the light of the solar spectrum is in the orange, and indeed that the sun looks orange, and if we close our eyes after gazing a moment at him when high up in the sky, we see a blue image. When the sun is low, his colour changes from orange to red, and this would explain the green tints so often seen in the cloudless parts of the sky at sunset. Possibly Mr. Glaisher, who has seen the sky through a thinner stratum of air than most of us, could help us to a solution.

Hampstead, April 24

\section{Curious Facts in Molecular Physics}

SOME of the phenomena of photography present features of a very curious nature, yet seem to be very little known to philosophers who devote their time to researches in molecular physics. For instance, when a glass plate coated with collodion containing an iodide--say iodide of cadmium - is dipped into a "bath" solution of nitrate of silver, strength twenty-five grains to the ounce, in from three to four minutes a good dense precipitate of yellow iodide of silver is formed in the spongy collodion film, and the plate is ready for photographic use. But, let a plate be covered with collodion containing bromide of cadmitum, (ten grains to the ounce) instead of iodide of cadmium, an immersion of ten or fifteen minutes is necessary to obtain a good film of bromide of silver, though the collodion skin upon the glass surface is only of the same thickness as in the former instance, and not only is this much longer immersion necessary, but the nitrate of silver solution must be increased in strength to about sixty grains to the ounce to get the best results. When the strength of the nitrate of silver is only twenty-five grains to the ounce, the bromide of silver forms more on the surface of the collodion than within it, and sometimes breaks away in scales from the collodion, and falls to the bottom of the bath

Lastly, let chloride of cadmium be used instead of the bromide in the collodion, the strength of the nitrate of silver must be increased to about one hundred grains to the ounce of water, and an immersion of thirty or forty-five minutes is necessary to get a good photographic precipitate of chloride of silver. In this case, when a weak nitrate of silver solution is used, an mneven precipitate is formed upon the plate, and the tendency to burst out of film in scales is seen as in the former instance.

The three kinds of films just described vary in their photographic properties. The iodide of silver film requires the shortest exposure in the camera to produce a good picture, the bromide of silver film requires a longer exposure, and the chloride of silver film requires the most prolonged exposure to light of all.

Again, the iodide of silver film is more liable than the others to spots and markings, when there are particles of dust or other impurities on the glass plate or in the solution used; bromide of silver is not nearly so delicately sensitive to such disturbing influences; the chloride of silver film is even less sensitive in this respect than the bromide surface.

The reason of the differences of time of exposure just men. tioned may possibly be accounted for on the supposition that chlorine binds itself to silver with more force than is exerted by bromine, and that the atom of bromine clings to the atom of silver with more tenacity than iodine clings to the metal. Hence the waves of light have more work to do in beating chlorine from silver than in beating iodine from silver. One very beautiful experiment, first made by Mr. M. Carey Lea, of Philadelphia, tends to prove that light will widen the distance between the hypothetical swinging atoms of iodine and silver, and that in darkness the atoms, with their attraction for each other thus partially overcome, will gradually fall together again. He prepared a film of absolutely pure dry iodide of silver, upon a glass plate, which film in the process of preparation had not been allowed to come into contact with the slightest trace of organic matter, in the washing water, or by any other means. On exposing such a film to light under a negative, and then applying what is known as the "alkaline developer," a picture came out; but if instead of developing the picture, the exposed plate were allowed to rest a day or two in the dark, the latent image died out, the film, so far as is known, returned to its primitive condition, and on exposure under another negative, a picture from it could be brought out, with no trace of the image impressed for a time through the first negative. The alkaline developer seems to "drink up" the iodine where its cohesion to the silver is loosened, thereby leaving a dark deposit of metallic silver, but where the light has not somewhat beaten the atoms asunder, the developer has no action, unless its strength be increased till it blackens the whole plate, whether the light has acted upon the film or not. The alkaline developer consists of a weak solution of pyrogallic acid, rendered alkaline by the addition of a few drops of carbonate of soda.

This is but one instance among many of the facilities offered by photographic phenomena to those who are trying to peer into the penumbral philosophical region of molecular physics.

WILLIAM H. HARRISON 